УДК 532.536

\title{
МУЛЬТИМАСШТАБНИЙ АНАЛІЗ МІКРО- ТА НАНОТЕЧІЙ
}

\author{
Авраменко А.О., член-кореспондент НАН України \\ Інститут технічної теплофізики НАН України, вул. Желябова, 2а, Київ, 03680, Україна
}

Представлено огляд та аналіз методів моделювання мікро- та нанопроцесів. Розглянуто особливості математичних моделей та межі їх використання в залежності від масштабу мікросистем.
Представлен обзор и дан анализ методов моделирования микро- и нанопроцессов. Рассмотрены особенности математических моделей и границы их использования в зависимости от масштабов микросистем.
A review is presented and analysis of methods for modeling micro- and nano flows is given. The features of mathematical models and the limits of their application are considered depending on the scale of microsystems.

Бібл. 30.

Ключові слова: процеси в мікро- та наноканалах, математичне моделювання.

$L$ - довжина ковзання,

$e-$ внутрішня енергія,

$\Theta$ - температура,

$g$ - сила тяжіння,

$n$ - кількість атомів, частинок,

$m$ - маса атому, частинки,

$u$ - швидкість,

$q$ - тепловій потік,

$x$ - координата,

$t$ - час,

Течії в мікроканалах суттєво відрізняються від течій в макроканалах. Процеси в мікроканалах не завжди можуть бути досліджені з використанням звичних моделей потоку, таких як рівняння Нав'є-Стокса 3 граничними умовами прилипання на границі рідина-тверде тіло, що регулярно і успішно застосовується для макропотоку. Градієнт тиску вздовж довгого мікроканалу при спостереженнях виявляється непостійним, а виміряна швидкість потоку $\epsilon$ вищою порівняно 3 прогнозом традиційної суцільної моделі потоку. Очевидно, що в мікропристроях домінують поверхневі ефекти. Відношення поверхні до об'єму для пристрою $з$ характерною довжиною в один метр - $1 \mathrm{~m}^{-1}$, в той час як для пристрою мікроелектронних систем, що має розмір 1 мікрон $-10^{-6} \mathrm{M}^{-1}$. Зменшення масштабів мікропристроїв може призвести до анулювання наближення суцільного середовища в цілому. Проковзування потоку, тепловий стрибок, розрідження, в'язка дисипація, стисливість, міжмолекулярні сили та інші нетрадиційні ефекти, можливо, доведеться брати до уваги, порівняно 3 використанням тільки основних принципів, таких, як збереження маси, другий закон Ньютона, збереження енергії.

Механіка мікрорідин є більш складною. Молекули більш щільно упаковані при нормальному тиску і температурі, а також більшими $є$ потенціали притягування або зчеплення між молекулами рідини, та між рідкою i твердою фазами, якщо характерний розмір потоку досить малий. У випадках, коли традиційна модель неперервного середовища не забезпечує точність розрахунків, використовуються більш затратні методи молекулярної динаміки або дисипативної динаміки часток. Але ці методи потребують значно більших обчислюваних затрат для реалістичного моделювання потоку, бо необхідно $\rho$ - щільність,

$\sigma_{\mathrm{ki}}-$ тензор напружень,

$\mathrm{Ec}$ - число Еккерта,

$\mathrm{Kn}$ - число Кнудсена,

$\mathrm{Pr}$ - число Прандтля,

$\mathrm{Re}$ - число Рейнольдса.

Індекси:

$i, j$ - номери частинок,

$w$ - стінка,

$s$ - стала.

враховувати надзвичайно велику кількість молекул чи часток. Можна визначити три різних підходи до середовища, що моделюється. Перший підхід розглядає рідину як суцільне середовище, гідродинаміка якого повністю описується рівняннями Нав'є-Стокса, теплообмін рівнянням теплопровідності Фур'є-Кірхгофа. В роботах $[1,2]$ зазначено, що традиційний підхід суцільного середовища справедливий за умови, що число Кнудсена $\mathrm{Kn}<0,1$. Причому, згідно роботи [1], в діапазоні $0,001<\mathrm{Kn}<0,1$, а за даними роботи [2] в діапазоні $0,01<\mathrm{Kn}<0,1$, необхідно використовувати граничні умови проковзування на стінках. Режими течії, що відповідають діапазону чисел Кнудсена $0,1<\mathrm{Kn}<10$ вважаються перехідними. В цих режимах зазвичай використовують статистичні методи, наприклад Монте-Карло, або методи, що базуються на рівнянні Больцмана. Системи, для яких число Кнудсена $\mathrm{Kn}>10$ вважаються сукупністю вільних молекул. Для їх моделювання використовуються методи молекулярної динаміки, дисипативної динаміки часток або фізико-хімічні методи.

\section{Модель суиільного середовища}

Модель суцільного середовища, що втілена в рівняннях Нав'є-Стокса, застосовується при чисельному моделюванні потоку. Модель ігнорує молекулярну природу газів і рідин i розглядає рідини, як суцільне середовище, що описується в термінах просторових і часових варіацій щільності, швидкості, тиску, температури та інших макроскопічних параметрів течії.

В принципі, модель суцільного середовища дає досить точні результати доти, доки локальні властивості, такі як щільність та швидкість можна визначити як середні 
за великими областями в порівнянні 3 мікроскопічною структурою рідини, але значно меншими в порівнянні 3 масштабами макроскопічних явищ. Саме за цих умов можливе використання диференціального обчислення для їх опису. Крім того, умови потоку не повинні бути занадто далекими від термодинамічної рівноваги. Перша умова виконується практично завжди, тоді як друга, як правило, обмежує істинність рівнянь суцільного середовища. Напруга зсуву та тепловий потік зазвичай повинні бути виражені в термінах більш низького порядку макроскопічних величин, таких як швидкість i температура, і найпростіші відносини дійсні тільки коли потік знаходиться поблизу термодинамічної рівноваги. Що ще гірше, традиційна умова прилипання рідини на межі твердого тіла й рідини порушується навіть раніше, ніж лінійна залежність між напругою і деформацією стає недійсною.

Для моделі суцільного середовища справедливі збереження маси, імпульсу i енергії. Гідродинамічний та тепловий стан системи можна виразити в кожній точці простору і часу у вигляді сукупності диференціальних рівнянь в частинних похідних наступним чином [1]

$$
\begin{aligned}
& \frac{\partial \rho}{\partial t}+\frac{\partial}{\partial x_{k}}\left(\rho u_{k}\right)=0 \\
& \rho\left(\frac{\partial u_{i}}{\partial t}+u_{k} \frac{\partial u_{i}}{\partial x_{k}}\right)=\frac{\partial \sigma_{k i}}{\partial x_{k}}+\rho g_{i}, \\
& \rho\left(\frac{\partial e}{\partial t}+u_{k} \frac{\partial e}{\partial x_{k}}\right)=-\frac{\partial q_{k}}{\partial x_{k}}+\sigma_{k i} \frac{\partial u_{i}}{\partial x_{k}}
\end{aligned}
$$

де $q_{k} \epsilon$ сумою векторів теплового потоку, що зумовлені теплопровідністю та випромінюванням. Зазвичай при використанні моделі суцільного середовища використовують граничні умови без проковзування на стінці.

Згідно [1] модель суцільного середовища справедлива, коли довжина вільного пробігу молекули $L \epsilon$ набагато меншою, ніж характерний розмір потоку $h$. При порушенні цієї умови, потік більше не перебуває поблизу рівноважного стану і лінійне співвідношення між напругою і швидкістю деформації, а також стан швидкості без проковзування більше не $є$ дійсними. Також порушується лінійна залежність між тепловим потоком і градієнтом температури і температурний режим на границі розділу твердого тіла й рідини стає стрибкоподібним. Як для рідин, так і для газів, використовується емпірична лінійна гранична умова Нав'є за якою дотичне ковзання швидкості на стінці $\left.\Delta u\right|_{w}$ $є$ пропорційним локальному зсуву

$$
\left.\Delta u\right|_{w}=u_{\text {рідини }}-u_{\text {стінки }}=\left.L_{s} \frac{\partial u}{\partial y_{w}}\right|_{\text {, }}
$$

де $\frac{\partial u}{\partial y_{w}} \mid-$ швидкість деформації на стінці.

В роботі [3] наведені результати чисельного дослідження тривимірного ламінарного потоку з проковзуванням і теплообміном в прямокутному мікроканалі, що має стінки $з$ постійною температурою. Для чисельних розрахунків були використані наступні безрозмірні вирази для визначення швидкості на стінці
$U=\left(\frac{2-\sigma_{v}}{\sigma_{v}}\right) \operatorname{Kn} \frac{\partial U}{\partial n}+\frac{3}{2 \pi}\left(\frac{(\gamma-1)}{\gamma}\right) \frac{\operatorname{Kn}^{2} \operatorname{Re}}{\operatorname{Ec}} \frac{\partial \theta}{\partial Z}$,

де $\frac{\partial U}{\partial n}$ - поперечний градієнт швидкості, а $\frac{\partial \theta}{\partial Z},-$ тангенціальний градієнт температури на стінці.

А також стрибок температури

$\theta-\theta_{\text {wall }}=\frac{2-\sigma_{T}}{\sigma_{T}}\left(\frac{2 \gamma}{\gamma+1}\right) \frac{\mathrm{Kn}}{\operatorname{Pr}} \frac{\partial \theta}{\partial n}$,

де $\sigma_{v}$ та $\sigma_{T}-$ коефіцієнти акомодації тангенціального імпульсу, що описують взаємодію молекул рідини зі стінкою.

Отже, 3 розвитком мікромасштабних теплових гідросистем, i досі існує необхідність досліджувати гідродинаміку й теплообмін потоку 3 проковзуванням в мікроканалах різної конфігурації. Метод суцільного середовища також досить точно описує процеси, що відбуваються в нанорідинах. На даний момент найбільш адекватною моделлю, що описує тепломасообмін та гідродинаміку нанорідин, є модель J. Buongiorno [4]

\section{Метод грат Больиммана ( LBM)}

Метод грат Больцмана (Lattice Boltzmann Method) метод гратчастого газу з дискретною кінетикою частинки, який використовує дискретну решітку і дискретний час [5]. LBM може також розглядатися як спеціальна кінцево-різницева схема кінетичного рівняння функції розподілу дискретної швидкості частинки. Ідея використовувати спрощене кінетичне рівняння для швидкості однієї частинки, щоб моделювати перебіг рідини, використовувалася в дослідженнях [6,7]. Ідея методу LBM полягає в наступному [8]. Розглядається імовірнісний розподіл $f(\mathbf{r}, \boldsymbol{v}, t)$, визначений таким чином, що $f(\mathbf{r}, \mathbf{v}, t) d \mathbf{r} d v$ визначає кількість частинок в момент часу $t$, що знаходяться в паралелепіпеді, обмеженому точками $\mathrm{r}$ i $\mathbf{r}+d \mathbf{r}$, швидкості яких лежать в інтервалі між v i v $+d \mathbf{v}$. Припустимо, що на всі частинки діє сила F. Тоді, якщо припустити, що частинки речовини не стикаються між собою, то зміна розподілу $f$ з часом має відбуватися на підставі рівняння Больцмана

$\frac{\partial f}{\partial t}+\frac{\partial f}{\partial \mathbf{r}} \cdot \mathbf{v}+\frac{\partial f}{\partial \mathbf{v}} \frac{\mathbf{F}}{m}=\Omega(f) d \mathbf{r} d \mathbf{v} d t$

де $\Omega(f)$ - оператор зіткнення.

B подальшому, метод LBM був вдосконалений i апробований на класичних задачах, таких як течія Пуазейля, або течія в каверні з рухомою кришкою $[9,10]$. Використана двовимірна решітка. Досить повний опис методу даний в [11]. Окрім задач гідродинаміки метод LBM також дає можливість моделювати процеси теплообміну [12-14].

\section{Модель молекулярної динаміки (MD)}

Основу методу молекулярної динаміки становить чисельне рішення класичних рівнянь Ньютона для системи взаємодіючих частинок:

$m_{i} \mathbf{a}_{i}=\mathbf{F}_{i}\left(\mathbf{r}_{i}\right), i=1 \ldots n$,

де $\mathbf{a}$ та $\mathbf{r}$ - прискорення та координати атому, $\mathbf{F}-$ сукупність діючих на атом сил. 
Сучасний розвиток обчислювальної техніки дозволяє моделювати динаміку молекулярних систем, що складаються 3 мільйонів частинок, 3 великим набором параметрів і різноманітних умов, що імітують фізичний експеримент [15]. Моделювання реальних фізичних систем, наприклад кристалів, або величезних біологічних молекул на базі методів МД являє собою дуже перспективний напрямок в найближчому майбутньому [16,17]. Нетривіальним аспектом застосування методів МД є оптимальний вибір потенціалів взаємодії, який визначає еволюцію системи $[18,19]$. Адекватний вибір потенціалу взаємодії і оптимізація його параметрів дуже важливі, наприклад, для моделювання міжфазних гетерогенних процесів (взаємодії кластерів 3 поверхнею, явища нуклеації парів на твердій основі і т.п.) [20].

\section{Метод дисипативної динаміки частинок (DPD)}

Серед складних систем, що вивчаються 3 використанням комп'ютерного моделювання, необхідно згадати системи, які часто складаються з рідкого середовища, в якому розчинені різноманітні об'єкти, їх називають складними флюїдами [21]. В роботі [22] наведена модель дисипативної динаміки частинок для аналізу гідродинаміки полімерних розчинів. Модель складається 3 частинок, що рухаються в неперервному середовищі. Цей домен ефективно відтворений в просторі за допомогою стандартним періодичним граничним умовам для імітації нескінченного середовища. Подібно до методу молекулярної динаміки конфігурація системи визначається всіма позиціями $\mathbf{r}_{i}$ та імпульсами $\mathbf{p}_{i}$. Система оновлюється 3 дискретним часовим кроком $\delta t$, що складається з фази зіткнення та подальшої фази поширення. При зіткненні фазові імпульси одночасно оновлюються відповідно до простого правила

$\mathbf{p}_{i}(t+\delta t)=\mathbf{p}_{i}(t)+\sum_{j} \Omega_{i j} \mathbf{e}_{i j}$,

де $\mathbf{e}_{i j}$ - одиничний вектор, спрямований від $j$ до $i$ частинки, а скаляр $\Omega_{i j}$ відображає передачу моменту від $j$ до $i$ частинки. В фазі поширення координати частинок визначаються співвідношенням

$$
\mathbf{r}_{i}(t+\delta t)=\mathbf{r}_{i}(t)+\frac{\mathbf{p}_{i}(t+\delta t)}{m_{i}} \delta t .
$$

Розвиток методу DPD знайшов в роботах [2326.] Універсальність методу DPD i теоретичне обгрунтування властивостей зробило його привабливим методом для крупнозернистих моделювань складних систем. Цікавий огляд застосування методу дається в роботі [27]. Одним з перших застосувань DPD було моделювання колоїдних суспензій. Колоїди можуть бути змодельовані в DPD, обмежуючи частинки в певній області, немов вони утворюють тверде тіло, що рухається крізь навколишню рідину. Крім того, DPD був використаний для моделювання полімерних систем. Застосуванням відповідних типів частинок можна побудувати складні архітектури полімерів, наприклад сополімерів. Реологічні властивості таких систем були вивчені і показують гарне узгодження 3 кінетичною теорією полімерів [28]. В роботі [29] використовували DPD для вивчення фазового розділення в бінарних незмішувальних рідинах. Нарешті, DPD використовується для вивчення самоорганізації та фазової поведінки ліпідного подвійного шару (lipid bilayers) мембран [30].

\section{ЛIТЕРАТУРА}

1. Gad-el-Hak M. The fluid mechanics of microdevices-the freeman scholar lecture // J. Fluids Eng. 1999. - vol. 121. - P. 5 - 33.

2. Karniadakis GE., Beskok A., Aluru A. Microflows and nanoflows: fundamentals and simulation. Springer, Berlin. -2005

3. Madhawa Hettiarachchi H.D., Golubovic M., William M. Worek, W.J. Minkowycz Three-dimensional laminar slip-flow and heat transfer in a rectangular microchannel with constant wall temperature // Int. J. Heat Mass Transfer . - 2008. - 51. -P. 5088-5096.

4. Buongiorno J. Convective transport in nanofluids, //J. Heat Transfer. - 2006. -128. -P. 240-250.

5. Chen S, Gary D. Doolen. Lattice Boltzmann method for fluid flows // Annu. Rev. Fluid Mech. - 1998. - № 30. P.329- 364

6. Broadwell JE. Study of rarefied shear flow by the discrete velocity method // J. Fluid Mech. - 1964. - №19. P. 401-414.

7. Inamuro T., Sturtevant B. Numerical study of discrete-velocity gases // Phys. Fluids. - 1990. -№2. P.2196- 2203.

8. Sukop, M.C., Thorne D.T., Jr. Lattice Boltzmann Modeling: An Introduction for Geoscientists and Engineers. Springer, Heidelberg, Berlin, New York. - 2006 (second printing 2007). - $172 \mathrm{p}$.

9. Chen S., Doolen G.D. Lattice Boltzmann method for fluid flows//Annu. Rev. Fluid Mech. -1998. - 30. P. 329-364.

10. Luo L.S. Unified theory of the lattice Boltzmann models for nonideal gases// Phys. Rev. Lett. -1998. - 81 (8). -P. 1618-1621.

11. Benzi R, Succi S, Vergassola $M$. The lattice Boltzmann equation: theory and applications// Phys. Rep. 1992. -222 (3). -P. 145-197.

12. Lallemand P., Luo L.S. Hybrid finite-difference thermal lattice Boltzmann equation// Int. J. Mod. Phys. 2003. - B 7 (1\&2). -P. 41-47.

13. Alexanders F., Chen S., Sterling J. Lattice Boltzmann thermo-hydrodynamics// Phys. Rev. E. -1993. 47. - R2249-R2252.

14. He X., Chen S., Doolen G.D. A novel thermal model for the lattice Boltzmann method in incompressible limit// J. Comput. Phys. -1998. - 146. -P. 282-300.

15. Qi L., Young W.L., Sinnott S.B. Polymerization via cluster E solid surface impacts: molecular dynamics simulations // J. Phys. Chem. B. -1997. - V. 101. - P. 6883. 16. Журкин В. Б., Полтев В. И., Флорентьев В. Л. Атом-атомные потенциальные функции для конформационных расчетов нуклеиновых кислот //Молекул. биология. -1980. -Т. 14, вып. 5. - С. 1116-1130.

17. Lewis J. P., Sankey O. F. Geometry and energetics of DNA basepairs and triplets from first principles quantum molecular relaxations // Biophis. J. - 1995. -V. 69. - 
P. $1068-1076$.

18. Alfonso D.R., Ulloa S.E., Brenner D.W. Hydrocarbon adsorption on a diamond (100) stepped surface // Phys. Rev. B. -1994 . -V. 49, No. 7. - P. 4948-4953.

19. Brenner D.W. Empirical potential for hydrocarbons for use in simulating the chemical vapor deposition of diamond films // Phys. Rev. B. -1990 . -V. 42, No. 15. -P. 9458-9471.

20. Jorgensen W.L. et al. Comparison of simple potential functions for simulating liquid water // J. Chem. Phys. -1983. -V. 79, No. 2. -P. 926-935.

21. Schiller D. Dissipative Particle Dynamics. A Study of the Methodological Background // - Diploma Thesis. 2005. - 180p.

22. Schlijper A.G., Hoogerbrugge P.J., Manke C.W. Computer simulations of dilute polymer solutions with the dissipative particle dynamics method // J. Rheol. - 1995. V.39, №3 - P.567-579.

23. Bonet Avalos J., Mackie A.D. Dissipative particle dynamics with energy conservation. // Europhys. Lett. 1997. - V.40, №2. -P.141-146.

24. Español P. Dissipative particle dynamics with energy conservation // Europhys. Lett. - 1997. - V.40, №6. P.631-636.

25. Bonet Avalos J., Mackie A.D. Dynamic and transport properties of dissipative particle dynamics with energy conservation // J. Chem. Phys. - 1999. - V.111, №11. P.5267-5276.

26. Willemsen S.M., Vlugt T.J.H., Hoefsloot H.C.J., Smit B. Combining Dissipative Particle Dynamics and Monte Carlo Techniques // J. Comp. Phys. - 1998. - V.147. P.507-517.

27. Warren P.B. Dissipative particle dynamics // Curr. Op. Coll. Interf. Sci. - 1998. - V.3, №6. - P.620-624.

28. Kong Y., Manke C.W., Madden W.G., Schlijper A.G. Modeling the rheology of polymer solutions by dissipative particle dynamics // Tribology Lett. - 1997. - V.3 - - P.133138.

29. Novik K.E., Coveney P.C. Using dissipative particle dynamics to model binary immiscible fluids // Int. J. Mod. Phys. C. - 1997. - V.8, №4. - P. 909-918.

30. Kranenburg $M$. Phase transitions of lipid bilayers: a mesoscopic approach / $\mathrm{PhD}$ thesis, Universiteit van Amsterdam. - 2004. 


\section{MULTISCALE ANALYSIS OF MICRO- AND NANO-FLOWS}

\section{Avramenko A.A.}

Institute of Engineering Thermophysics of the National Academy of Sciences of Ukraine, vul. Zhelyabova 2a, Kiev, 03680 , Ukraine.

Multiscale analysis of micro and nano-flows was carried out. The features of mathematical models and the limits of their application are considered depending on the scale of microsystems. The estimation of the possibility of using mathematical models of different levels for studying hydrodynamics and heat transfer in micro and nano devices is given. References 30.

Key words: processes in micro- and nano channels, mathematical modeling

1. Gad-el-Hak M.(1999) The fluid mechanics of microdevices-the freeman scholar lecture. J. Fluids Eng. vol. 121. P. 5 - 33 .

2. Karniadakis GE., Beskok A., Aluru A. 2005. Microflows and nanoflows: fundamentals and simulation. Springer, Berlin.

3. Madhawa Hettiarachchi H.D., Golubovic M., William M. Worek, W.J. Minkowycz. 2008. Threedimensional laminar slip-flow and heat transfer in a rectangular microchannel with constant wall temperature. Int. J. Heat Mass Transfer. 51. P. 5088-5096.

4. Buongiorno J. 2006. Convective transport in nanofluids, J. Heat Transfer. 128. P. 240-250.

5. Chen S, Gary D. Doolen. 1998. Lattice Boltzmann method for fluid flows. Annu. Rev. Fluid Mech. № 30. P. $329-364$

6. Broadwell JE. 1964. Study of rarefied shear flow by the discrete velocity method. J. Fluid Mech. №19. P. 401-414.

7. Inamuro T., Sturtevant B. .1990. Numerical study of discrete-velocity gases. Phys. Fluids. №2. P.2196 - 2203.

8. Sukop, M.C., Thorne D.T., Jr. 2006. Lattice Boltzmann Modeling: An Introduction for Geoscientists and Engineers. Springer, Heidelberg, Berlin, New York. (second printing 2007). $172 \mathrm{p}$.

9. Chen S., Doolen G.D. 1998. Lattice Boltzmann method for fluid flows. Annu. Rev. Fluid Mech. 30. P. 329364.

10. Luo L.S. 1998. Unified theory of the lattice Boltzmann models for nonideal gases. Phys. Rev. Lett. 81 (8). -P. 1618-1621.

11. Benzi R, Succi S, Vergassola M. 1992. The lattice Boltzmann equation: theory and applications. Phys. Rep. 222 (3). -P. 145-197.

12. Lallemand P., Luo L.S. 2003. Hybrid finitedifference thermal lattice Boltzmann equation Int. J. Mod. Phys. - B 7 (1\&2). -P. 41-47.

13. Alexanders F., Chen S., Sterling J. 1994. Lattice Boltzmann thermo-hydrodynamics. Phys. Rev. E. 47. R2249-R2252.
14. He X., Chen S., Doolen G.D. 1998. A novel thermal model for the lattice Boltzmann method in incompressible limit. J. Comput. Phys. 146. P. 282-300.

15. Qi L., Young W.L., Sinnott S. (1997) Polymerization via cluster E solid surface impacts: molecular dynamics simulations. J. Phys. Chem. B. V. 101. P. 6883.

16. Zhurkin V.B., Potlev V.I., Florentev V.L. 1980. Atomatomnye potentsialnye funktsii dlia konformatsionnyh rastchetov nukeinovyh kislot. Molekul. Biologia. T. 14, V. 5. P. 1116-1130 (Rus).

17. Lewis J.P., Sankey O.F. 1995. Geometry and energetics of DNA basepairs and triplets from first principles quantum molecular relaxations. Biophis. J. -V. 69. - P. 1068-1076.

18. Alfonso D.R., Ulloa S.E., Brenner D.W. 1994. Hydrocarbon adsorption on a diamond (100) stepped surface. Phys. Rev. B. V. 49, No. 7. P. 4948-4953.

19. Brenner D.W. 1990. Empirical potential for hydrocarbons for use in simulating the chemical vapor deposition of diamond films. Phys. Rev. B. V. 42, No. 15. P. 9458-9471.

20. Jorgensen W. L. et al. 1983. Comparison of simple potential functions for simulating liquid water. J. Chem. Phys. V. 79, No. 2. P. 926-935.

21. Schiller D. 2005. Dissipative Particle Dynamics. A Study of the Methodological Background. Diploma Thesis. 180 p.

22. Schlijper A.G., Hoogerbrugge P.J., Manke C.W. 1995. Computer simulations of dilute polymer solutions with the dissipative particle dynamics method. J. Rheol. V.39, №3 P.567-579.

23. Bonet Avalos J., Mackie A.D. 1997. Dissipative particle dynamics with energy conservation. Europhys. Lett. V.40, №2. P.141-146.

24. Español P. 1997. Dissipative particle dynamics with energy conservation. Europhys. Lett. V.40, №6. P.631-636. 25. Bonet Avalos J., Mackie A.D. 1999. Dynamic and transport properties of dissipative particle dynamics with energy conservation. J. Chem. Phys. V.111, №11. P.52675276.

26. Willemsen S.M., Vlugt T.J.H., Hoefsloot H.C.J., Smit B. 1998. Combining Dissipative Particle Dynamics and Monte Carlo Techniques. J. Comp. Phys. V.147. P.507-517. 27. Warren P.B. (1998) Dissipative particle dynamics. Curr. Op. Coll. Interf. Sci. V.3, №6. P.620-624.

28. Kong Y., Manke C.W., Madden W.G., Schlijper A.G. 1997. Modeling the rheology of polymer solutions by dissipative particle dynamics. Tribology Lett. V.3. P.133138.

29. Novik K.E., Coveney P.C. 1997. Using dissipative particle dynamics to model binary immiscible fluids. Int. J. Mod. Phys. C. V.8, №4. P. 909-918.

30. Kranenburg M. 2004. Phase transitions of lipid bilayers: a mesoscopic approach. $\mathrm{PhD}$ thesis, Universiteit van Amsterdam. 